\title{
The 1998 Agreement
}

\author{
Context and Status
}

COLIN HAR VEY

\subsection{Introduction}

Northern Ireland remains a special arrangement, with distinctive legal, political and constitutional features. Its particular circumstances were reflected and confirmed in the 1998 Agreement and what has happened since it was agreed and endorsed in concurrent referendums on the island of Ireland. One of the intriguing aspects of the Brexit debate is the role that the 1998 Agreement continues to play in the discussions. The status it is accorded in practical terms, and in the political rhetoric of the negotiations, defies easy classification, and legal analysis risks underplaying the scale of its real-world impact. It is lauded around the world, most notably in the United States, and the defence of the 1998 Agreement, and the associated peace process, became a priority for the EU throughout the Brexit process. But the text is often deployed by opposing actors in the public sphere for diverging reasons, which can make the reconciliation of competing claims based on the 1998 Agreement difficult, especially where domestic legal implementation is absent.

The conflict in, and about, Northern Ireland has been absorbed into the interpretative struggles over the meaning of a text that contains significant ambiguity. Little about this is news for lawyers and would be familiar to literary critics and theologians. But it has a sharpened edge in the contested constitutional politics of a post-conflict society where precision and clarity matter in distinctive ways. Law has its own internalized ideas about what counts as a 'good legal argument' or even a 'good lawyer', and these can develop and be influenced by the community of interpreters. The aim of this chapter is to reflect on the context and legal status of the 1998 Agreement, with a view to framing its place as 
a foundational document when considering the Protocol. Although written with a legal audience in mind, there is no suggestion that this is either the only or even the most helpful lens through which to understand it.

\subsection{Context and Content}

The Agreement is the result of a peace process and a political process spanning decades and is a sophisticated attempt to accommodate competing ethno-national objectives in a credible and sustainable way. Many of its core concepts were prefigured in earlier texts; it did not simply emerge in 1998. It is a peace and political agreement that leads multiple lives. Viewed narrowly within the political and constitutional dynamics of the UK, it can be construed as part of a story of decentralization, modernization and reform. Standard accounts of UK constitutional law risk perpetuating that limited view. The Agreement is better understood, however, as a foundational constitutional document that reflects the complex political reality of a deeply divided transitional society, with solutions offered that acknowledge the origins of conflict in the fraught relationships across 'these islands'. Such an understanding was, however, always likely to create friction with an exclusively internal UK legal narrative.

The 1998 Agreement is a multi-party agreement, signed on 10 April 1998 and approved in referendums on the island of Ireland on 22 May 1998. It contains commitments by the British and Irish governments around its implementation in domestic law and a British-Irish Agreement (a bilateral treaty) that entered into force more than a year after the document was signed. ${ }^{1}$ While the overall principled framework has remained securely in place, alterations to the application of the arrangements have been made, indicating that pragmatic evolution is possible. The Agreement has been supplemented by other agreements since 1998, notably the St Andrews Agreement $2006 .{ }^{2}$ There have been significant changes including, for example, to the operation of the Northern Ireland Executive, the appointment of the First Minister and the deputy First Minister, ${ }^{3}$ the number of

1 Agreement between the Government of Ireland and the Government of the United Kingdom of Great Britain and Northern Ireland, Irish Treaty Series No 18 of 2000, entry into force 2 December 1999.

2 The St Andrews Agreement, October 2006, www.gov.uk/government/publications/the-standrews-agreement-october-2006.

3 Northern Ireland (St Andrews Agreement) Act 2006, s 8. 
Members of the Northern Ireland Assembly (MLAs) ${ }^{4}$ and some as a result of Brexit. ${ }^{5}$

The 1998 Agreement is structured around a three-stranded approach, locating the Northern Ireland conflict in the context of the need to establish stable political institutions within Northern Ireland (Strand One), the relationship between Northern Ireland and Ireland (Strand Two, the North-South dimension) and the relationship between Ireland and Britain (Strand Three, the East-West dimension). Commitments are framed by a 'declaration of support' and a section on 'constitutional issues'. The Agreement also addresses matters such as 'rights, safeguards and equality of opportunity', 'decommissioning', 'security', 'policing and justice', 'prisoners' and 'validation, implementation and review'. It contains annexes dealing with draft legislation to be taken forward by both governments as well as a British-Irish Agreement that provides an international legal grounding. ${ }^{6}$

The design of the 1998 Agreement is itself of considerable interest, as is its structure. For example, where legal precision is demanded on constitutional guarantees, it is provided in the text. Its legitimacy and strength reside not merely in the fact that it was agreed by most of the political parties in Northern Ireland ${ }^{7}$ but also in its being anchored in an all-island exercise in popular sovereignty connected to the achievement of sustainable peace. That popular basis of support on the island of Ireland lends a formidable weight in the arena of political constitutionalism, and politics in general. ${ }^{8}$

For the purpose of understanding its relationship with the Protocol, several elements of the Agreement are worth highlighting. First, the participants in the negotiations, in recommending the Agreement for endorsement, committed to a range of overarching principles. These include 'partnership, equality and mutual respect', 'reconciliation, tolerance, and mutual trust, and ... the protection and vindication of the human rights of all', the use of 'exclusively democratic and peaceful means' including 'opposition to any use or threat of force by others for any political purpose' and

4 The Agreement notes 108, but this has been reduced to 90, Assembly Members (Reduction of Numbers) Act (Northern Ireland) 2016.

${ }^{5}$ For example, EUWA Act 2018, ss 10-12 and sch 2; EUWAA 2020, ss 21-24 and sch 3.

6 The preamble to the British-Irish Agreement provides: 'Wishing to develop still further the unique relationship between their peoples and the close co-operation between their countries as friendly neighbours and as partners in the European Union ...' above $n 1$.

7 The Democratic Unionist Party (DUP) did not participate in the negotiations.

${ }^{8}$ The 'yes' vote was 71.1 per cent in the North and 94.4 per cent in the South, www.ark.ac.uk /elections/fref98.htm. 
recognition of 'equally legitimate ... political aspirations'. There is no suggestion that these values necessarily cohere into a singular narrative, but they still regularly enter public debate, not least over the acceptability of the Protocol, with different participants selecting the principles that suit their own political or policy agenda at the time.

Second, the constitutional core of the Agreement contains a formula for dealing with the right of self-determination and the principle of consent. Respecting the Agreement requires that the only way that a change will take place in the constitutional status of Northern Ireland, as a constituent part of the UK, is by way of a process that involves an exercise in concurrent consent by voters North and South, with the outcome to be determined on a simple majority vote in each jurisdiction. If people vote for change, then there is a 'binding obligation' on both governments 'to introduce and support in their respective Parliaments legislation to give effect to that wish'. The Protocol is explicit that it is 'without prejudice' to these provisions of the Agreement, and that it 'respects the territorial integrity' of the UK.'

Third, as we have seen, this is not only an internal Northern Ireland arrangement; it is a deliberately three-stranded approach. The obvious implication of this approach is that it highlights just how distinctive the governance of Northern Ireland already was before Brexit. It underlines the centrality of power-sharing between 'nationalists' and 'unionists', the close relationality among the different parts of 'these islands', and the connection to the EU that was clearly contemplated in the Agreement.

Strand One deals with 'democratic institutions in Northern Ireland' (the Northern Ireland Assembly and Executive), including their nature, safeguards, operation, as well as their relationship to other institutions. The Assembly is elected on the basis of proportional representation (STV) and there are power-sharing mechanisms in place to ensure cross-community participation. For example, MLAs must register a designation ('nationalist', 'unionist' or 'other'), which is then used to assist the functioning of the power-sharing arrangements. Strand Two agrees the establishment of a North-South Ministerial Council as a vehicle for 'consultation, cooperation and action within the island of Ireland' between the Northern Ireland Executive and the Irish government. Notably, the Council has a role in considering 'institutional or cross-sectoral matters' and that includes those 'in relation to the EU' and 'the implementation of EU policies and programmes and proposals under consideration in the EU framework'. The

9 Article 1(1) and (2). 
Agreement is clear on the need to 'ensure that the views of the Council are taken into account and represented appropriately at relevant EU meetings'. Six North-South Implementation Bodies have been established, including the Special European Union Programmes Body, and there are six areas of agreed co-operation (agriculture, education, environment, health, tourism and transport). Strand Three covers the institutional expression of 'EastWest' relationships through the British-Irish Council (including representatives of the governments of the UK and Ireland, the devolved administrations (Scotland, Wales and Northern Ireland) and the Isle of Man and the Channel Islands) and the British-Irish Intergovernmental Conference.

Fourth, the Agreement contains a dedicated section with commitments on human rights and equality. ${ }^{10}$ The Agreement led to significant changes in the UK and Ireland in this regard, including the establishment of the Northern Ireland Human Rights Commission and the Equality Commission for Northern Ireland, an express agreement to incorporate the European Convention on Human Rights (ECHR), as well as an agreement on the creation of a new public sector statutory equality duty. It also provided the basis for a Northern Ireland Bill of Rights process to build on the ECHR. The Joint Committee of the Human Rights Commissions on the island of Ireland was envisaged as providing a useful 'forum for consideration of human rights issues in the island of Ireland'. We shall see that these issues featured in discussions around the impact of Brexit and led to an important provision in the Protocol.

Consideration of the Protocol has to include, then, how in particular it interacts with the power-sharing, relational, and rights and equality dimensions of what was agreed and endorsed in 1998. Although there is much value in internal UK comparisons, it is more often unhelpful to view Northern Ireland solely through a devolutionary lens. Northern Ireland is not just like Scotland and Wales and its distinctive role within an asymmetrical and pluralist 'Union state', and on the island of Ireland, must be appreciated.

\subsection{Legal Status}

\subsubsection{International Law}

The 1998 Agreement contains a British-Irish Agreement that replaces the Anglo-Irish Agreement 1985. ${ }^{11}$ The British-Irish Agreement has four

10 British-Irish Agreement above n 1.

11 British-Irish Agreement above n 1, Article 3. 
articles and two annexes (annex 1 is the 'Agreement Reached in the MultiParty Talks' and annex 2 is a declaration on citizenship). ${ }^{12}$ The political agreement between the political parties and the governments is therefore an intrinsic part of a bilateral and binding international legal agreement entered into by both governments. The British-Irish Agreement replicates the 'constitutional issues' section of the Agreement; ${ }^{13}$ the governments 'affirm their solemn commitment to support, and where appropriate implement, the provisions of the Multi-Party Agreement'; ${ }^{14}$ and several conditions must be met before it could enter into force. ${ }^{15}$ The British-Irish Agreement provides no mechanism for enforcement or oversight other than through the operation of bilateral engagement, in particular through the British-Irish Intergovernmental Conference. ${ }^{16}$

The UK and Ireland are both state parties to the Vienna Convention on the Law of Treaties $1969 .{ }^{17}$ Various obligations arise from this, in particular the obligation of 'good faith' performance. ${ }^{18}$ Domestic law is not a valid reason for failure in this regard. ${ }^{19}$ The British-Irish Agreement 'shall be interpreted in good faith in accordance with the ordinary meaning to be given to the terms of the treaty in their context and in the light of its object and purpose'. ${ }^{20}$ Subsequent agreements regarding application or interpretation may be taken into account ${ }^{21}$ as can practice 'which establishes the agreement of the parties regarding its interpretation'. ${ }^{22}$

The question of whether the British-Irish Agreement has been implemented in good faith still arises, occasionally resulting in rival claims about what this requires. This is not solely a debate about whether a political agreement is being honoured. It is a discussion about the rule of international law in the bilateral relations between states: both the UK and Ireland are bound as a matter of international law by the

2 British-Irish Agreement above n 1.

${ }_{13}$ Article 1.

14 Article 2.

15 Article 4.

16 The Agreement contains a section on 'Validation, Implementation and Review'. Ireland does not accept the jurisdiction of the International Court of Justice in any legal dispute with the UK in regard to Northern Ireland.

171155 UNTS 331, entry into force 27 January 1980.

18 Article 26.

19 Article 27.

${ }^{20}$ Article 31(1).

21 Article 31(3)(a).

22 Article 31(3)(b). 
commitments undertaken. As we shall see, this becomes significant in the light of the application of the Protocol.

Although the international legal underpinning matters, in practical terms, it is the reception of these obligations in domestic law that tends to matter most, and to which the attention now turns. Unsurprisingly given the present constitutional status of Northern Ireland, much of the focus is on the UK, but the Irish government is a co-guarantor and also agreed to make significant changes, with ongoing implications for discussions of Brexit and the Protocol. The Agreement has not been incorporated in its entirety into the domestic law of either Ireland or the UK.

\subsubsection{United Kingdom}

The Northern Ireland Act 1998 (NI Act 1998) is the legislative vehicle for the domestic incorporation of aspects of the Agreement. The Agreement itself does not have the direct 'force of law' in the UK. ${ }^{23}$ The starting point therefore, from the perspective of domestic law in the UK, is the NI Act 1998 and the way it gives effect to the Agreement. ${ }^{24}$ The constitutional significance of the NI Act 1998 for Northern Ireland has been recognized. In Robinson $v$ Secretary of State for Northern Ireland and Others Lord Hoffmann stated: ${ }^{25}$

In choosing between these two approaches to construction, it is necessary to have regard to the background to the 1998 Act. It was passed to give effect to the Belfast Agreement concluded on Good Friday 1998. This agreement was the product of multi-party negotiations to devise constitutional arrangements for a fresh start in Northern Ireland. . . The 1998 Act is a constitution for Northern Ireland, framed to create a continuing form of government against the background of the history of the territory and the principles agreed in Belfast.

For Lord Bingham it was also clear: 'The 1998 Act does not set out all the constitutional provisions applicable to Northern Ireland, but it is in effect a constitution. ${ }^{26}$ The recognition of the particular constitutional circumstances of Northern Ireland in Robinson retains its significance, and

23 For example, see Stephens LJ in In re McCord [2020] NICA 23, [45], regarding the provisions of the 1998 Agreement which refer to a border poll as not themselves having the force of law.

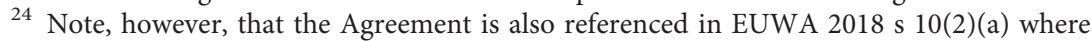
there is an attempt to protect North-South co-operation on the island of Ireland.

25 [2002] UKHL 32, [25]. A point underlined even further at [33].

26 Ibid [11]. 
concepts developed in the case have proven influential. ${ }^{27}$ Although there is, understandably, a tendency to view this from the perspective of other devolution arrangements, ${ }^{28}$ this has only limited applicability to the special constitutional status that is in place for Northern Ireland. This constitutional framing matters because otherwise there may be a tendency in discussions of the Protocol to neglect or underplay the particularity of Northern Ireland's special status.

The legislation is intended to implement the Agreement, but it does not give effect to all its parts. ${ }^{29}$ The obligation in the 1998 Agreement of 'rigorous impartiality' is not, for example, included in domestic law. ${ }^{30}$ The British-Irish Agreement and the 1998 Agreement as a whole are regarded as aids to the interpretation of the NI Act 1998, as an international treaty and as a political agreement. ${ }^{31}$ Debate continues on whether the Agreement has been faithfully implemented in domestic law in the UK, and the absence from the Act of some key concepts is often noted. The fact that the Protocol consistently refers to the 1998 Agreement, rather than the NI Act 1998 is, therefore, significant.

\subsubsection{Ireland}

Both states are dualist in their approach to international law, but Ireland has distinctive constitutional arrangements. ${ }^{32}$ Ireland has a codified constitution (Bunreacht na hÉireann ${ }^{33}$ ) that is open to amendment through an established referendum process. ${ }^{34}$ As with the UK, although the Agreement was not incorporated directly into domestic law, specific

27 See, for example, In re McCord above n 23 and JR80's Application [2019] NICA 58.

28 The approach adopted in Robinson contrasts with the cursory treatment of the 1998 Agreement in $R$ (Miller and another) $v$ Secretary of State for Exiting the European Union [2017] UKSC 5, [128], where a majority in the Supreme Court appears to miss significant dimensions of the Agreement.

29 The Act refers to the 'Belfast Agreement' by which it 'means the agreement reached at multi-party talks on Northern Ireland set out in Command Paper 3883', Northern Ireland Act 1998 s 98 (1).

30 British-Irish Agreement above n 1 Article 1(v). But note the role this concept played in In re McCord above n 23.

${ }^{31}$ In re McCord above $\mathrm{n} 23$ [47]. See also In re Allister and others $v$ Secretary of State for Northern Ireland [2021] NIQB 64.

32 See, for example, Article 29(6): 'No international agreement shall be part of the domestic law of the State save as may be determined by the Oireachtas.'

33 The Irish language is the 'national language' and thus constitutionally recognized as the first official language, Article 8(1).

${ }^{34}$ Article 47. 
changes were made to reflect the obligations undertaken and the commitments made. ${ }^{35}$

The Irish government agreed in the negotiations leading to the 1998 Agreement to propose changes to the Irish Constitution to be put to a referendum. ${ }^{36}$ This constitutional change was achieved through an amendment to Article 29, which allowed the state to consent to be bound by the British-Irish Agreement and provided for the eventual replacement of Articles 2 and $3 .{ }^{37}$ Article 2 now contains a commitment to those born on the island of Ireland to be 'part of the Irish Nation', an entitlement also applicable to 'all persons otherwise qualified in accordance with law to be citizens of Ireland'. The scope of this birthright obligation was subsequently narrowed following a referendum in $2004 .^{38}$ The new version of Article 3 is intended to soothe anxieties about any territorial claim to Northern Ireland. ${ }^{39}$ It reflects an imperative to 'unite all the people who share the territory of the island of Ireland' with the recognition 'that a united Ireland shall be brought about only by peaceful means with the consent of a majority of the people, democratically expressed, in both jurisdictions in the island'. ${ }^{40}$ The changes also made clear the ability of Agreement institutions to exercise powers and functions across the island. ${ }^{41}$

The Irish government agreed to 'take steps to further strengthen the protection of human rights in its jurisdiction' and this led to the establishment of the Irish Human Rights Commission (now the Irish Human Rights and Equality Commission), the domestic incorporation of the ECHR (at the sub-constitutional level), ${ }^{42}$ the ratification of the Framework Convention on National Minorities, as well as advances on equality and non-discrimination. The 1998 Agreement contains the

${ }^{35}$ For example, the British-Irish Agreement Act 1999, dealing with the North-South Ministerial Council, the British-Irish Council and the North-South Implementation Bodies. There are Amendment Acts to reflect subsequent agreements.

36 To confirm that the British-Irish Agreement had entered into force. See the Agreement 'Constitutional Issues' Annex B and British-Irish Agreement Article 4.

37 See Nineteenth Amendment of the Constitution Act 1998. A challenge to the proposals was rejected by the Irish Supreme Court in Riordan v An Taoiseach [1999] IESC 1.

38 See Article 9(2) and the Twenty-Seventh Amendment of the Constitution Act 2004.

39 The previous version referred to the 're-integration of the national territory'. Its replacement is notable, and the 'shared island' language adopted has informed developments since, including the establishment of a Shared Island Unit within the Department of the Taoiseach. For further information: www.gov.ie/en/publication/de9fc-shared-island/.

40 Article 3(1).

${ }^{41}$ Articles 29(7)(2) and 3(2).

42 European Convention on Human Rights Act 2003. 
notion of 'equivalence', the idea being that the steps taken by the Irish government would 'ensure at least an equivalent level of protection of human rights as will pertain in Northern Ireland'. While the concept is used in the Agreement to refer to what is required from the Irish government, there is merit in a generous and purposive interpretation that acknowledges the underlying rationale: that all those on the island of Ireland should enjoy an equivalent range of guarantees, and that current or future constitutional status should not have detrimental rights-based consequences. Brexit gives 'equivalence' additional relevance, with the well-founded concern that the two jurisdictions on the island may begin to diverge even more significantly.

\subsection{Conclusion}

The aim of this chapter is to provide an overview of the 1998 Agreement and address questions around its legal status. Its international and domestic reception is not easily explained in terms of simple legal categorization as it has taken on a foundational constitutional quality as a peace, as well as a political, agreement. For domestic legal purposes in the UK and Ireland, it is primarily a political agreement and a bilateral treaty that has resulted in major constitutional and legislative reform. Subsequent agreements have brought changes, and the NI Act 1998, for example, has been heavily amended. But the Agreement retains its iconic standing. The fact that the EU was willing to place its protection at the heart of its negotiating strategy signals a widespread determination not to permit Brexit to destabilize a successful peace project. And the tendency of those who remain sceptical about its existence to wield it when required suggests that it has durability. Although almost everyone now anchors their argumentative strategy around its defence, there is disagreement about what it means, so the contestations ahead, and the varied arenas within which they take place, will be required to consider and to settle on the most plausible legal interpretations. 